\title{
History of Pharmaceutical Development in Nepal
}

\section{Dharma Prasad Khanal ${ }^{1}$}

\section{${ }^{1}$ M Pharm PhD}

Address for Correspondence: Manmohan Memorial Institute of Health Sciences, Kathmandu 16, Soalteemode, Nepal, Tel: 00977-9851077038, Email: drdharmakhanal@gmail.com/ drdpk@mmihs.edu.np.

\section{Abstract}

The historical event of the development of pharmacy was started during ancient Lichchhavi ruler Amshu Berma date back to 605-620 AD when a Ayurvedic hospital was established. In 16411674 AD, King Pratap Malla started ayurvedic medicine production unit in the royal place. Modern allopathic medicines were introduced in Nepal in 1816 AD after Suguali Treaty and establishment of British residency in Nepal. Allopathic medicine manufacturing was started in 1969 in private sector and a government undertaking Royal Drug Limited was established in 1972. Department of Drug Administration (DDA), a drug regulating Agency of the country was established according to the Drug Act in 1979. The pharmaceutical education was started in Nepal with the commencement of the Proficiency Certificate Level, a two and half year program (Intermediate in Pharmacy that is similar to Diploma of Pharmacy) at the Institute of Medicine, Tribhuban University in 1972. Santabhavan Hospital (present patan Hospital that was established in 1956) is pioneer to start hospital Pharmacy service in Nepal followed by Tansen Mission hospital Palpa that was started operation in 1959.

\section{Introduction}

The history of health and hospital development dates back to the ancient Nepal or Lichchhavi period. In the reign of the Amshu Verma (605-620 AD) one of the historical document found in $604 \mathrm{AD}$ has mentioned about the Aarogyashala or hospital (probably Ayurvedic), but no elaborate explanations has been found [1]. The Ayurvedic and Traditional System of medicine in Nepal are closely related to Himalayan civilization. Chinese as well as Tibetan Medicine had a large influence especially in the life of the peoples living in the highest mountains. Hindu priests were influenced from Banaras (India) and used to practice the herbal remedies written in the book "Shikarnath "The Newars are the proud inhabitants of the valley of Kathmandu and are 
indigenous people belonging to the area and mostly dwell in the valleys and are close knit community proud of their heritage and way of life had also a rich culture of traditional medicine.

A large portion of the people believed on faith healing like Dhami-Jhankri and Devi- Deuta (God and Goddesses). During Pratp Malla regime (1641-1674 AD), an ayurvedic medicine production unit was established in Hanuman Dhoka Darbar and Rana Prime Minister Jung Bahadur Rana shifted that unit to Thapathali in 1846 in Singha Darbar compound. At that time medicine were manufactured only for royal families. Latter the ayurvedic medicine manufacturing unit was named Singh Durbar Vaidya Khana. King Tribhuvan (1906-1955) first arranged the distribution of those medicines to the general public [2].

The allopathic medicine (modern medicine) introduced in Nepal after Suguali Treaty and establishment of British residency in 1816 AD (1873 BS). A small clinic was established in residency compound for staff and that serve the local people. Bir hospital was established in 1890 AD (1947 BS) [1, 3]. After establishment of Bir Hospital, few other hospitals were established. So the demand of modern medicine increased gradually. With this Drug wholesale and retail entrepreneurs' organization for import of drugs were established. According to Department of Drug Administration, there were 400 medical shops in 1979 AD that rose 7000 in 1992. In 1964, Royal Drug Research Laboratory (RDRL) was established in 1964 and the production unit of which is evolved AS Royal Drug Limited in 1972 [3]. In the same year Nepal Pharmaceutical Association as a professional organization with the participation of pharmacists and other professionals (Chemists, Botanists, Biochemists etc) was established. The first pharmaceutical industry from private sector was to be built in the name of Nepal Pharmaceutical Works at Godavari in 1969 but it could not run due to site problem. Establishment of RDRL was the starting of the pharmaceutical development in Nepal. Tribhuban University, Institute of Medicine started the Proficiency Certificate in Pharmacy - a two and half year intermediate course in Pharmacy that is now phase out with the establishment of more than 25 Diploma of Pharmacy College around the country in the umbrella of Council for Technical Education and Vocational Training (CTEVT), Ministry of Education, Government of Nepal, Sanothimi, Bhaktpur [4]. Undergraduate course of pharmacy first started in Nepal was started in Kathmandu University, Dhulikhel in 1994. National Drug Policy in Nepal was promulgated in 1995. 
With the effort of RDRL, Drug Act 1978 was passed by government and promulgated on $25^{\text {th }}$ October 1978. According to the Act Royal Drug Research Laboratory was recognized as National Government for quality control of drugs and Department of Drug Administration (DDA) was established according to the Act in 1979 under the Ministry of Forest and Soil Conservation [5]. APPON (Association of Pharmaceutical Producers of Nepal) was established in the year 1990 AD by the pharmaceutical entrepreneurs with the view to facilitate, enhance and improve the service of the pharmaceutical companies in co-ordination with different government bodies, medical fraternity and pharmaceutical business houses. Nepal Pharmacy Council Act was passed by Parliament of Nepal in 2000 (2057 BS) and first Nepal Pharmacy council the professional and regulatory body for pharmacists in Nepal was organized [6].

According to Bhupendra Badur Thapa (Former Director General of DDA) the pharmaceutical development in Nepal can be divided in three epochs: From 1950-1980 legislation first phase , 1980 to 2000 industrial development second phase and 2000 on ward hospital pharmacy third phase [7].

\section{History of Pharmaceutical Regulation in Nepal [5]}

According to the Drug Act 1978, Royal Drug Research Laboratory was recognized as National Government agency for quality control of drugs and Department of Drug Administration (DDA) was established according to the Act in 1979 under the Ministry of Forest and Soil Conservation. The objectives of Drug Act were, to prohibit the misuse or abuse of drugs and allied pharmaceutical materials as well as the false or misleading information relating to efficacy and use of drugs and to regulate and control the production, marketing, distribution, exportimport, storage and utilization of those drugs which are not safe for the use of the people, efficacious and of standard quality. Under the Drug Act 1978, the following rules and regulation and codes have been implemented as supporting tools for the active enforcement of Drug Act 1978.

- Regulation on Constitution of Drug Consultative Council and Drug Advisory Committee, 2037

- Drug Registration Regulation, 2038

- Interrogation and Inspection Regulation, 2040

- Codes on Drug Manufacturing, 2041 


\section{- Drug Standard Regulation, 2043}

So the objectives of DDA is to regulate all functions relating drug like misuse and abuse of drugs and its raw materials, to stop false and misleading advertisement and make available safe, efficacious and quality drug to the general public by controlling the production, marketing, distribution, sale, export-import, storage and use of drugs. Now, DDA has set up the ten strategies to fulfill the objectives (ref: http://www.dda.gov.np). National Medicines Laboratory, formally Royal Drug Research Laboratory (RDRL), is the principal body of Government of Nepal for testing, analysis and quality control of drugs. There is a provision of the formation of two apex advisory bodies in Ministry of Health and Population namely, Drugs Advisory Council and Drugs Advisory Committee in Drug Act 1976. The main function of the Council is to provide advice to the Government of Nepal on theoretical and administrative matters relating to drugs, taking into account of the main object to protect the national interest and make the country selfreliant by checking the import based production process and being more dependent on indigenous herbs etc. Whereas the main function of Committee is to give advice to the Department of Drugs Administration on technical matters as to the research, development and control of drugs.

In accordance with the objectives of the National Health Policy 1991, to fulfill the commitment of Government of Nepal (GoN), to provide "health for all" and to improve and manage by establishing co-ordination among the governmental, non- governmental and private organizations involved in the activities related to drug production, import, export, storage, supply, sales, distribution, quality assessment, regulatory control, rational use and information flow, the National Drug Policy 1995 has been promulgated for implementation.

\section{History of Pharmaceutical Education in Nepal [8-11]}

The pharmaceutical education was started in Nepal with the commencement of the Proficiency Certificate Level, a two and half year program (Intermediate in Pharmacy that is similar to Diploma of Pharmacy) at the Institute of Medicine, Tribhuban University in 1972 with the leadership of a British Pharmacist Paul David Spivey. But Bachelor of Pharmacy could not be 
started in institute of Medicine. The Bachelor of pharmacy (B. Pharm) program was started in Kathmandu University in 1994 after twenty two years of PCL program. The B. Pharm programs later were started at Tribhuvan University in 2000, at Pokhara University in 2001 and at Purbanchal University affiliated Asian college in 2007.

Till the academic year 2070/71, Tribhuban University has seven affiliated pharmacy colleges and central department, Pokhara University has two affiliated colleges plus one central department, Purbanchal University has seven affiliated colleges only and Kathmandu University has no any affiliation. So in total twenty pharmacy colleges enrolling about 630 undergraduate pharmacy students annually in Nepal. Nepal Pharmacy Council Act Was passed by parliament in 2057 BS (2000) and immediately council body was formed to regulate the pharmacy profession in Nepal.

\section{History of Allopathic Medicine Manufacturing in Nepal [3, 12-14]}

Pharmaceutical industry history was started in Nepal, when Chemidrug Industries Pvt. Ltd established a production unit 1969 at Kathmandu. Is the first pharmaceutical industry which started production was Chemidrug Industries Private Limited (CDPL) began its service in 1970 as pioneer pharmaceutical industry in Nepal. The production unit of RDRL was evolved as Royal Drug Limited that started to manufacture allopathic medicine in 1972. Most of the Nepalese national pharmaceutical industries were established in early eighties (Manoj, Everest, Lomus, NPL) and early nineties. About seven large volume parental companies (Pashupati Chemical, Nepal Pharmaceutical, Himal Pharmaceuticals, Bagmati Pharmaceuticals, Rainbow Pharmachem, BHK Pharma and Vijayadeep Pharmaceuticals) were established, but all most all of them are failure and closed. According to DDA, up to 2013 there are 45 human and 8 veterinary allopathic drug Manufacturing companies in Nepal. Good Manufacturing Practice is a term that is recognized worldwide for the control and management of manufacturing and quality control testing of Pharmaceutical Products. Nepali Pharmaceutical Industries are also manufacturing medicines following GMP Guidelines and thus are providing quality products and services. Out of 48 running Nepalese Pharmaceutical Industries 33 industries are already certified with WHO-GMP. Fourteen new pharmaceutical companies are coming in near future.

APPON (Association of Pharmaceutical Producers of Nepal) was established in the year 1990 $A D$ by the pharmaceutical entrepreneurs with the view to facilitate, enhance and improve the 
service of the pharmaceutical companies in co-ordination with different government bodies, medical fraternity and pharmaceutical business houses. Today, it has 50 pharmaceutical companies as its members, who govern the $40 \%$ of Nepalese pharmaceutical Market Share, 32 of which are certified with WHO-GMP and others in process of it. APPON from the day of its establishment is driving towards the destination to produce safe, efficacious and economical products with high quality to serve the health sector of Nepal. To promote the Nepalese Pharmaceutical industries in the Global Market it is also supporting for export. It is also helping the pharmaceutical industries in the technical and technological advancement which ultimately aid for the development of Health segment of Nepal. Today, it has 48 pharmaceutical companies as its members, who govern the $40 \%$ of Nepalese pharmaceutical Market Share, 32 of which are certified with WHO-GMP and others in process of it. Actually pharmaceutical industries flourish during the moist conflict in Nepal from early nineties of the twenty century. Today, Nepalese industries are putting their efforts and six of them had already taken "Certificate of Pharmaceutical Products (COPP) for export of some of their products in international market. The total consumption of medicines in Nepal in different categories is given in the table No.1.

\begin{tabular}{|l|l|}
\hline \multicolumn{2}{|l|}{ Table No: 1 - The total consumption of medicines 2069/70 (2012/13) fiscal year } \\
\hline Total Consumption & 18 Arab \\
\hline Total domestic production & 8.5 Arab $(47.22 \%)$ \\
\hline Out of 8.5 Arabs, contribution of different sectors \\
\hline Allopathic preparation & 7.5 Arabs $(41.66 \%)$ \\
\hline Ayurvedic preparation & 0.5 Arabs $(2.78 \%)$ \\
\hline Veterinary preparation & 0.5 Arabs $(2.78 \%)$ \\
\hline
\end{tabular}




\section{History of Hospital Pharmacy Practice in Nepal [1, 15-16]}

Santabhavan Hospital (present patan Hospital that was established in 1956) is pioneer to start hospital Pharmacy service in Nepal followed by Tansen Mission hospital Palpa that was started operation in 1959. During seventies and eighties of last century, government hospitals dispensed the extemporal preparations like Cough Mixture, Carminative Mixture, Magnesium Carbonate mixture, Kaolin Mixture, Sulphur Ointment, Boroglycerine, Gentian violet solution, Mercurochrome solution, Acriflavin solution etc. But there were no assistant pharmacists or pharmacist and mostly AHW (Assistant Health worker) were performing the job. First time, in 2036 BS (1979), Ministry of Health , Government of Nepal, created the posts for two assistant pharmacists (Qualification: PCL Pharmacy passed from TU, Institute of Medicine) In Mechi Zonal Hospital Bhadrapur and Mahindra Hospital Bharatpur. There were the posts of graduate pharmacists (officers) in Kanti Hospital and Bir Hospital. But they were neither doing dispensing nor patient counseling. In Bir hospital those posts are still today. In 2007 less than 8\% of registered pharmacists and 37\% pharmacy assistants worked in hospital and community pharmacies. There are more than 100 hospitals existing in the country but only approximately 15 hospitals have a presence of hospital pharmacist. And in many of the medical colleges of the country, hospital pharmacy is totally absent and/or established just for formality. Very Few private and teaching hospitals are having good hospital pharmacy today (Manipal Hospital Pokhara, Dhulikhel Community Hospital, Model Hospital). Mission hospitals (Patan Hospital and Tansen Hospital) have a classical hospital pharmacy with their own system.

\section{History of Drug Distribution and Sales}

Nepal Chemists and Druggists Association, an organization of business firms involved in pharmaceutical retailing as well as in wholesaling was formed in the year 1973 with the main objective of enforcing the price uniformity. NCDA is purely a non-government organization of pharmaceutical trade profession [17].

\section{Further Reading}

1. Marasini B R, Hospital Development in Nepal: Past and Present. Journal of Nepal Medical Association 2003; 42: 306-311. 


\section{Review Article}

2. Gewali M. B, Aspects of Traditional Medicine in Nepal. Institute of Natural Medicine, University of Toyama, Japan.

3. Thapa B.B et al (editors), Nepalese Pharmaceutical Guide 1993.

4. $\quad$ NPC News Letter, Vol. 2 Issue 1 September 2007. Nepal Pharmacy Council

5. http://www.dda.gov.np (last updated 23rd October, 2013)

6. http://www.nepalpharmacycouncil.org.np/

7. www.youtube.com/watch?v=gv6ob9fDzcU

8. Www.Pharma-IQ.com (Information available in early December 2013)

9. Saha Dibyajyoti, Glimpse of Pharmaceutical Education in Nepal. International Journal of Pharmacy Teaching \& Practices 2013, Vol.4, Issue 1, 438-441.

10. http://www.ku.edu.np/science/

11. http://pu.edu.np/university/faculty-of-science-and-technology/

12. http://www.dda.gov.np/industry.php (last updated 23rd October, 2013)

13. http://www.appon.org.np/(Information available in early December 2013)

14. Pharma Nepal, Quarterly Bulletin of APPON

15. Heydon S. Mountains and medicines: history and medicines use in rural Nepal. Southern Med Review (2011) 4; 1:4-8 doi:10.5655/smr.v4i1.77.

16. Mukhtar Ansari. Teaching hospitals of Nepal need to have own hospital pharmacy with pharmacy services. IJPTP, 2013, 4(3), 695-696.

17. http://www.ncda.org.np/about-us/company-profile

18. Dharma Prasad Khanal and Sarita Khanal(Book): History of Pharmacy- Medication and healing. Department of Pharmacy, Manmohan Memorial Institute of Health Sciences, 2013. 